\title{
Reforms about the Teaching of Scientific Instruments in Higher Education
}

\author{
Yong-Hui WU', a , Qing-Ren QIAN ${ }^{2}$, Zhi LIN ${ }^{2}$, Jun-Sheng LIU², \\ Xiao-Wen ZHANG ${ }^{2}$ and Deng-Guang $\mathrm{YU}^{2, \mathrm{~b}}$ \\ ${ }^{1}$ The Department of Mechanical Engineering, Guangxi Technological College of Machinery and \\ Electricity, Nanning 530007, China \\ ${ }^{2}$ School of Material Science and Engineering, University of Shanghai for Science and Technology, \\ Shanghai 200093, China \\ Emial: aahuiwyh@163.com, bydg017@usst.edu.cn
}

Keywords: Higher education, Scientific instrument, Reform, Teaching model.

Abstract. The traditional manner for teaching of scientific instruments in higher school is often separate process, i.e. giving the lecture about theory in class, doing show-how experiment in laboratory and involving little with the real applications. Based on the teaching of ultraviolet-visible spectrophotometer, here a new model for effectively imparting both knowledge and skills about scientific instruments to college students is proposed. The key elements in this model include: 1) systematization of the lectures about scientific instruments; 2) effective integration of experimental practices in laboratory with knowledge learning in the classroom based on the scientific instruments; and 3) infiltrating the daily life experience for real applications in explaining scientific instruments.

\section{Systematization of the Lectures about Scientific Instruments in Higher Education}

One of the most common manners for teaching the usage of scientific instruments in college and university is to give the lecture about the fundamental theories in the classrooms, later the related experiments are carried out by the students or just shown-how by the teaching assistants in laboratories after a long time period. As far as the real applications of these scientific instruments, it is often a thing happened when the students go to work. This manner is very inefficient in teaching the students both theories and practices because the three steps for learning are separate.

Today, it is time to reform this outdated status in the teaching of scientific instruments in higher education. The learning of fundamental knowledge, the related experience of carrying out the experiments and the real applications can be unified together around the instrument and the supporting theory, and are finished alternatively.

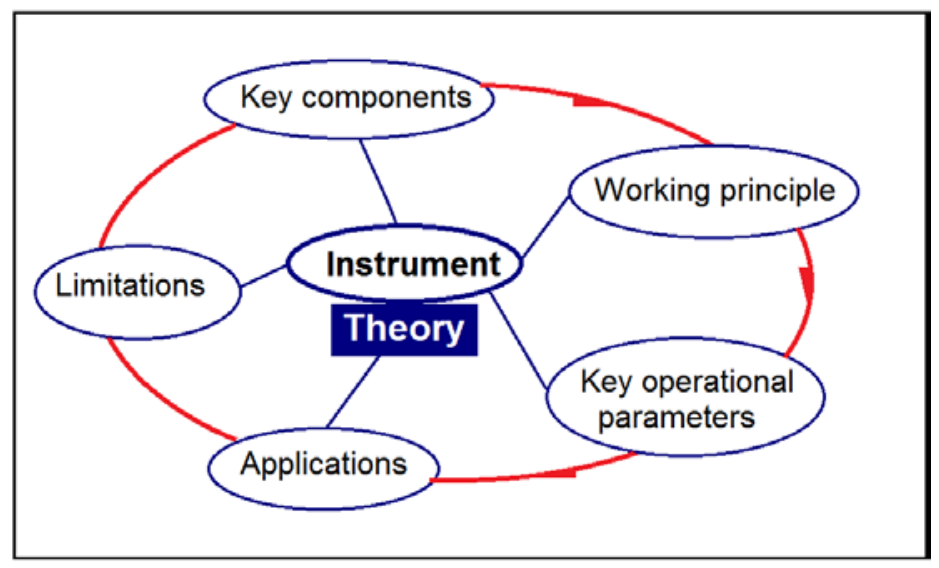

Figure 1. The most important elements in teaching knowledge about scientific instruments, which should be imparted to the students in a systematic manner.

Shown in Fig. 1 is the most important elements in teaching knowledge about scientific instruments, 
which should be imparted to the students in a systematic manner. After the simple teaching of theory, the key components of the scientific instruments, their working principles, their key operational parameters, the potential real applications and even their limitations can be all taught in the laboratory. These contents can be imparted to the students right after the classroom teaching, and certainly the students can go back to the classroom to summarize their learning and experience for systematic grasp.

\section{Effective Integration of Experimental Practices in Laboratory with Knowledge Learning in the Classroom Based on the Scientific Instruments}

To explain how to integrate the teaching of theory with scientific experiment in laboratory, a common laboratory instrument - ultraviolet-visible-near infrared (UV-vis-NIR) spectrophotometer is exploited as an example, which is frequently utilized in the quantitative analysis [1-3]. Shown in Fig. 2 is the working principle a UV-vis-NIR spectrophotometer, including all its key components (light, monochromator, sample cell and the detector).

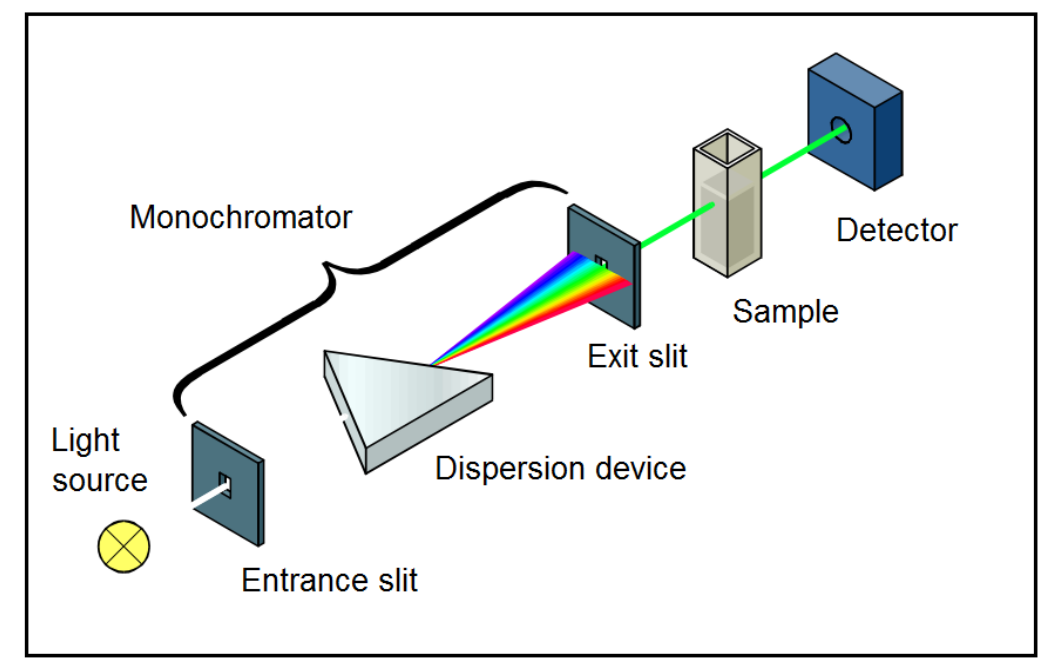

Figure 2. The key components in a ultraviolet-visible spectrophotometer and its working principles for measuring materials' concentration.

The most fundamental theory supporting this instrument is the Beer-Lambert Law, which reflects the relationship between a material absorbance and its concentration. In the Beer-Lambert Law, A is equal to $\log \left(\mathrm{I}_{0} / \mathrm{I}\right)=\varepsilon c L$, where $\mathrm{A}=$ Absorbance (optical density), $\mathrm{I}_{0}=$ Intensity of light on the sample cell, I = Intensity of light leaving the sample cell, c = concentration of solute, $\mathrm{L}=$ length of sample cell $(\mathrm{cm}), \varepsilon=$ molar absorptivity (molar extinction coefficient). According to this equation, $\varepsilon$ is a constant reflecting the property of measured material, $\mathrm{L}$ can be fixed at a constant value (most often it is $1 \mathrm{~cm}$ ), thus, the value of absorbance has a linear relationship with material concentration.

Through these explanations with the UV-vis-NIR spectrophotometer as a teaching tool, the students not only are deepened about the fundamental knowledge about the Beer-Lambert Law, but also are familiar with the key components of the instrument and the working principles. Furthermore, it is also very easy to tell them the key parameters for a successful measurement, which comprises two important steps. One is the reasonable selection of the sample cell for scanning, and another is the determination of the maximum wavelength of the material absorbance within UV-vis-NIR region for creating a standard calibration equation.

In general, when light interacts with a substance it can do so in one of three main ways: (1) The light may be absorbed (A); (2)The light may be transmitted (T); (3)The light may be scattered(S), and apparently the value of $\mathrm{A}+\mathrm{T}+\mathrm{S}$ is $100 \%$. When UV-vis-NIR absorbance is exploited to detecting a material concentration, the smaller that interference from the cell and the environment, the better accurate the achieved results. Thus, the material comprised the cell should have little absorbance at 
the detected wavelength. Shown in Fig. 3, glass has a significant absorbance when the wavelength is smaller than $350 \mathrm{~nm}$, and fused silica has little absorbance when the wavelength is larger than $200 \mathrm{~nm}$. Based on these facts, fused silica cells (expensive) can be utilized for detection over a wide wavelength range of $200 \mathrm{~nm}$ to $800 \mathrm{~nm}$, whereas glass cells (cheap and the most commonly used ones) can only be utilized for the measurement with a maximum absorbance bigger than $350 \mathrm{~nm}$.

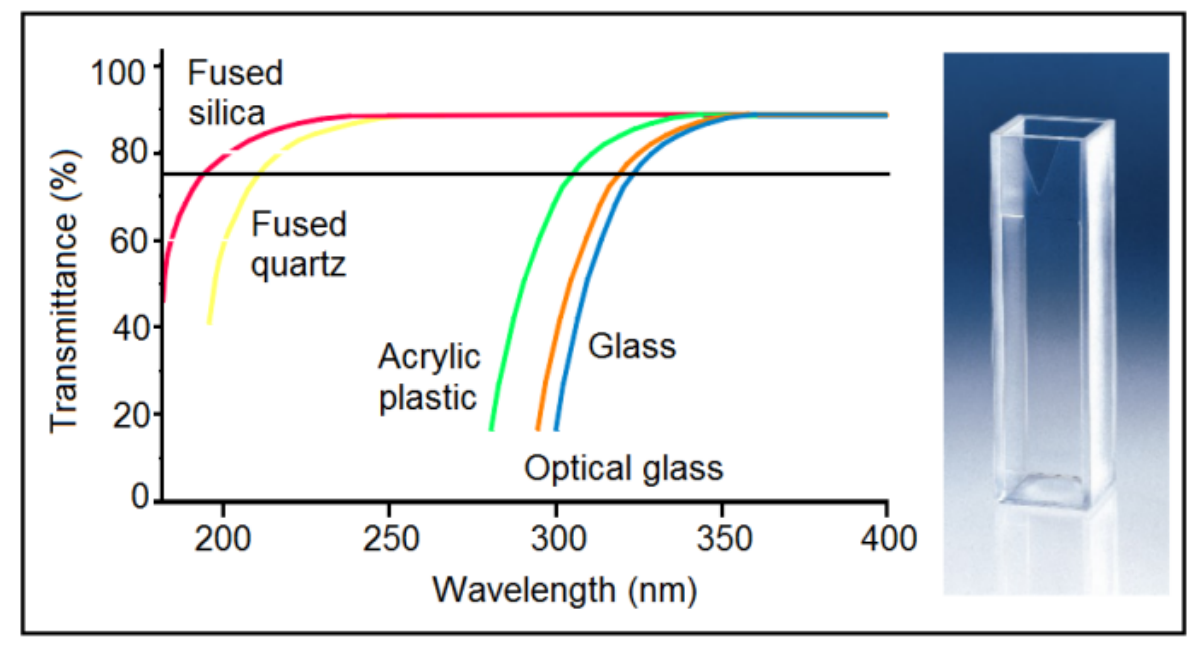

Figure 3. The fundamental knowledge about the reasonable selection of sample cells for carrying out the UV-vis detection experiments, the right inset is a digital image of a fused silica cell.

\section{Infiltrating the Daily Life Experience for Real Applications in Explaining Scientific Instruments}

Based on the knowledge about theory, key components, working principle and key parameters about the scientific instruments, it should be not a difficult thing for the students to carry out the quantitative experiments themselves [4-7]. However, the integration of daily life experience of the students can impress them a lot and makes the teaching yielding twice the result with half the effort. One example is shown in Fig. 4, which is about the detection of an active pharmaceutical ingredient (API) in a commercial tablet brought by one of the students.

First of all, a fused silica cell was used to scan the API solution with one tablet in $100 \mathrm{~mL}$ distilled water. The absorbance is shown in Fig. 4a, which is an abnormal absorbance curve and suggests that the API concentration was excessive. Later, the solution was diluted 10 times and a routine absorbance curve is right shown in Fig. 4b. A maximum wavelength of $\lambda_{\max }=374 \mathrm{~nm}$ was utilized for quantitative analysis. These real materials in our daily lives have drawn the students' great attention. They are eager to know how much is the drug content and does it meet the national standard. Thirdly, a series of standard solutions with known concentrations of the API were prepared and subjected the UV-vis-NIR scanning. Based on the data about concentrations and their corresponding absorbance values, a standard calibration equation of $A=0.00998 \mathrm{C}+0.07053$ was successfully built (with a correlation coefficient R of 0.9997 and a linear range of $5 \mu \mathrm{g} / \mathrm{mL}$ to $50 \mu \mathrm{g} / \mathrm{mL}$.

The average value of the repeated six times was $40.65 \pm 3.34 \mu \mathrm{g} / \mathrm{mL}$, suggesting a total content of over $40 \mathrm{mg}$ in one tablet. According to the specifications from the factory that has produced this product, the detected tablet was an qualified product. Interest is the best teacher. The infiltration of daily life experience has greatly provoked the students' interests, promoting them to self-study and making the explanations about scientific instruments more easily. 

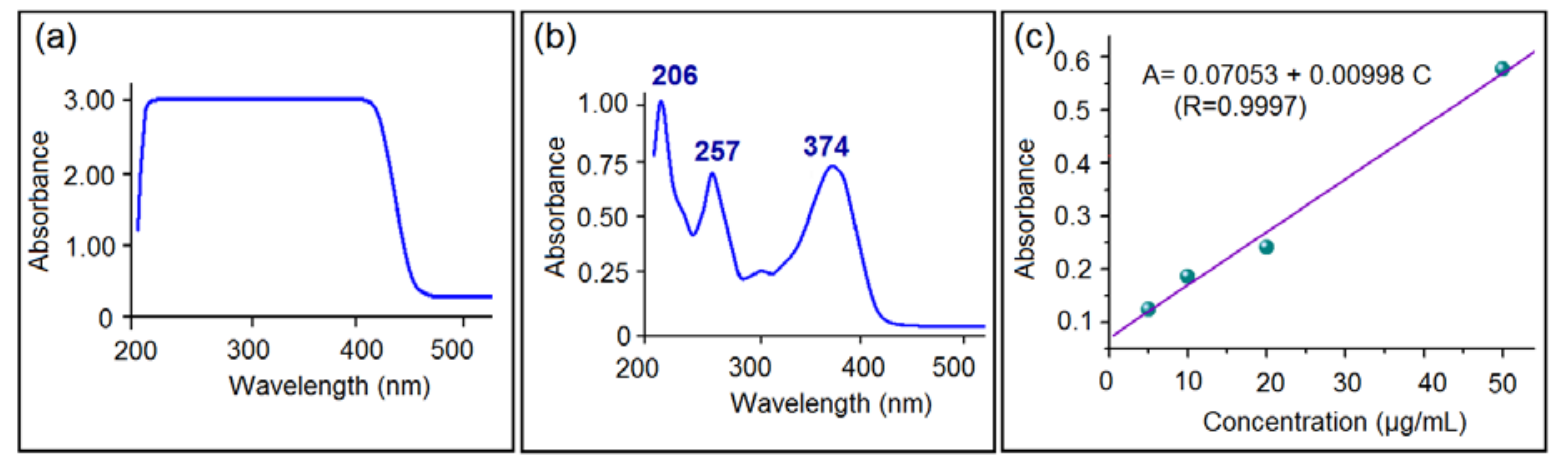

Figure 4. A successive steps for measuring the drug content from a commercial pharmaceutical tablet carried with one of the students: (a) the excessive drug in the sample; (b) the selection of appropriate peak wavelength for detection; and (c) a standard calibration for measurement of drug concentration in un-known samples.

\section{New Model for Reforming the Traditional Manner in the Teaching of Scientific Instruments in Higher Education}

For senior students in colleges and universities, one of the most important things is to do self-study and cultivate lifelong learning ability. The traditional model of teaching scientific instruments to them is a separate manner with lectures in class, experiments in laboratory, and applications in the society after they graduate. This model is already out of date and should be reformed. Based on above-mentioned situations, a new model for reforming the traditional way in the teaching of scientific instruments in higher education is proposed in Fig. 5. The laboratory can be exploited as a key teaching place with the applied scientific instruments as the teaching materials. The theory, the experiment, and also the potential application can be melt together to be transferred to the students. This should benefit the students to foster their capability of connecting theory with practice in a simple way. Certainly, the laboratory experiments can be designed in a step-by-step way, i.e. from show-how of the teachers, to the do-it-yourself of the students, and finally encouraging the students to find real applications themselves.

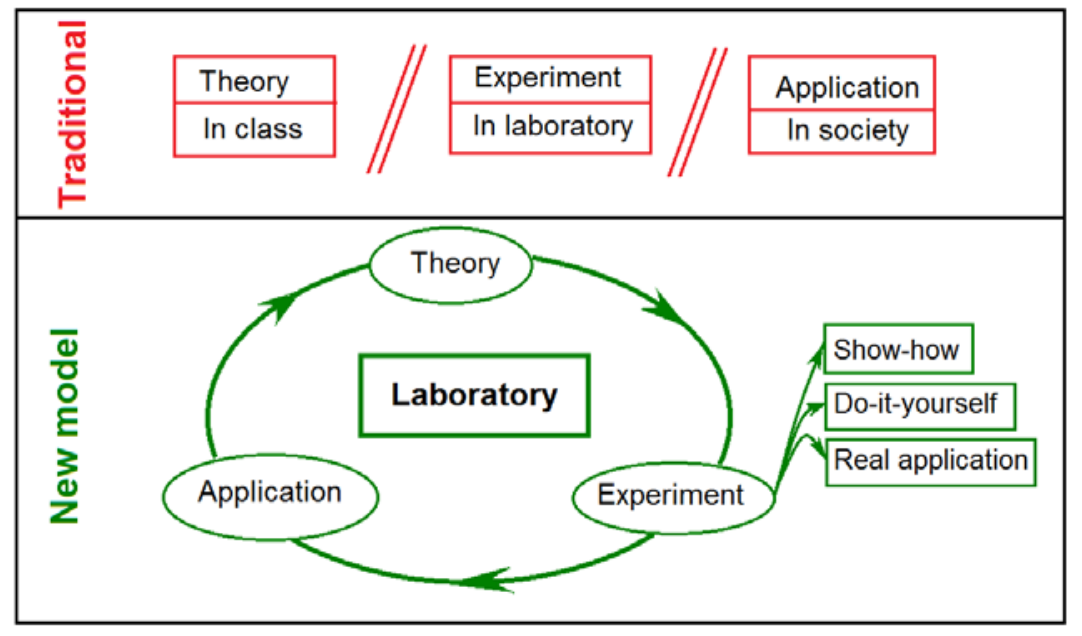

Figure 5. The comparison of the traditional model and the proposed method for reforming the teaching of scientific instruments in higher education.

\section{Conclusions}

The traditional separate model in teaching scientific instruments in higher school can not meet the demand of cultivating undergraduate students' working skills and all-round qualities. Using a 
UV-vis-NIF spectrophotometer as a teaching material, a new model for effectively imparting both knowledge and skills about scientific instruments to students is proposed. In realizing the new model, several measures have been put forward to provoke the students' interests and foster their ability of self-learning and life-long learning. These methods include systematization of the lectures about scientific instruments, effective integration of experimental practices in laboratory with knowledge learning in the classroom based on the scientific instruments, and infiltrating the daily life experience for real applications in explaining scientific instruments.

\section{Acknowledgments}

The financial supports from the following projects are appreciated: the Training Project for Excellent Young and Middle-aged Backbone teachers of Higher Schools in Guang-Xi Province in China, the Natural Science Foundation of China (No. 51373101), 2016 key project on teachers teaching development in USST (CFTD16001Z), the College Student Innovation Project of USST (Nos. XJ2016234 and SH2016176), and the Project of Teaching Reform of Higher Education in Gunag-Xi Province in China (No. 2012JGA333).

\section{References}

[1] B. Li, Z. Hua, Z. Liu, Study on preparing microcapsule in high-voltage electrostatic field, J. Uni. Shanghai Sci. Technol. 22 (2000) 189-193.

[2] Y.H. WU, C. Yang, X.Y. Li, J.Y. Zhu, D.G. Yu, Medicated nanofibers fabricated using NaCl solutions as shell fluids in a modified coaxial electrospinning, J. Nanomater. 2016 (2016) Article ID 8970213, 12 pages.

[3] H.F. Wen, C. Yang, D.G. Yu, X.Y. Li, D.F. Zhang, Electrospun zein nanoribbons for treatment of lead-contained wastewater, Chem. Eng. J. 290 (2016) 263-272.

[4] D.G. Yu, C. Yang, M. Jin, G.R. Williams, H. Zou, X. Wang, S.W. Annie Bligh, Medicated Janus fibers fabricated using a Teflon-coated side-by-side spinneret, Colloid. Surf. B 138 (2016) 110-116.

[5] C. Yang, D.G. Yu, D. Pan, X.K. Liu, X. Wang, S.W. A. Bligh, G.R. Williams, Electrospun $\mathrm{pH}$-sensitive core-shell polymer nanocomposites fabricated using a tri-axial processes, Acta Biomater. 35 (2016) 77-86.

[6] D.G. Yu, X.Y. Li, X. Wang, J.H. Yang, S.W.A. Bligh, G.R. Williams, Nanofibers fabricated using triaxial electrospinning as zero order drug delivery systems, ACS Appl. Mater. Interf. 7 (2015) 18891-18897.

[7] F. Xu, Y. Xu, D.G. Yu, Zero-order controlled release nanofibers fabricated using coaxial electrospinning with polymer dilute solution as a sheath fluid, J. Uni. Shanghai Sci. Technol. 37 (2015) 165-168. 